\title{
Analysis of Hydrogen Production from wind Power Generation from the Perspective of Industrial Security
}

\author{
Jie Qi \\ Postdoctoral Programme of China Center for Industrial Security Research,Beijing Jiaotong \\ University, China \\ qqijjie@163.com
}

\begin{abstract}
Keywords:wind power industry; clean energy; utilization of electric hydrogen;storage of wind power; clean energy

Abstract:Hydrogen as "secondary energy" is the new technology development direction and the research important topic.Using of wind power for water electrolysis can eliminate the carbon dioxide emissions in the traditional hydrogen production,and achieve real green and clean production. At present foreign electric hydrogen production has accumulated more mature technology,while China will embrace the hydrogen production industry from wind power industry,and electric hydrogen production is the carrier of hydrogen or other forms of storage consumption, which has a realistic significance for the wind power industry development and industrial security.
\end{abstract}

\section{Introduction}

Since the beginning of twenty-first Century, China's wind power industry has rapid development in the country's macro policy guidance and support. According to the released data from the Global Wind Energy Council, the global wind power cumulative installed capacity has reached 432419MW by the end of 2015, while China's total installed capacity has reached 145.1GW. But at the same time, we should also see the great hidden dangers behind the achievements, such as the unreasonable layout, consumptive difficult, abandoned wind power rationing and other serious problems.So how to deal with wind power industry to ensure the new energy efficient, recycling and sustainable development is of great strategic significance to national construction and industrial safety.

Hydrogen as "secondary energy" not only can reduce the dependence on fossil energy and consumption, and reduce pollution emissions and improve power consumptive ability, but also can promote the technology transformation of oil chemical industry, and coal chemical industry, which is the reasonable choice in the low carbon era .

In 2015,the national wind power industry continues to maintain a strong momentum of growth with new installed capacity of 32.97 million kilowatts.Annual installed capacity has reached a high point, and the cumulative net installed capacity accounted for $8.6 \%$ of the total generating capacity. [1]

However,the national wind power average utilization hours of 1728 hours drops compared to 172 hours at the same period in 2015.The abandoned wind power rationing situation has further aggravated, annual abandoned wind power is 33.9 billion kwh, with an increase of 21.3 billion kilowatts in 2014 , average disposable wind rate is $15 \% .{ }^{[1]}$ The proportion of data is also constantly widening.

Hydrogen is a highly efficient, clean and renewable energy, which has a prominent position in the future planning of global energy utilization, which has a great impact on the global ecological environment and social development.The biggest problem facing the development of wind power industry is the consumption.At present foreign electric hydrogen production has accumulated more mature technology,while China will embrace the hydrogen production industry from wind power industry,and electric hydrogen production is the carrier of hydrogen or other forms of storage consumption, which has a realistic significance for the wind power industry development and industrial security. 


\section{The development of hydrogen production at the present stage}

The advantage of hydrogen energy. Hydrogen is a renewable and clean energy and the global future alternative to fossil fuels, whose the combustion is water, which do not produce other pollutants or

carbon dioxide.It has the huge development potential and broad prospects.

The development of hydrogen production at the present stage. he traditional hydrogen production is still the main mode of supply.At present domestic petrochemical, coal chemical industry use natural gas or coal and other raw materials to prepare hydrogen.Although the technology is mature, and the relatively cost is low,but does not conform to the development trend of domestic and international environment. The new energy access should not be associated with other environmental damage based on natural gas or coal and other raw materials of producing hydrogen, will cause a large amount of greenhouse gas emissions, which bring the state and enterprises discharge pressure. At the same time, the construction of this super large manufacturing facilities requires a large number of resource consumption.

The ideas and future direction of wind power industry development can not only the outputting.Because of the wind energy utilization of geographical features, we should look forward to planning many kinds of wind energy utilization mode of transformation in order to break through the current wind energy and other new energy development bottleneck.So it can get an energy saving, clean, sustainable and comprehensive utilization road.

The current large-scale wind farm directly connected to the way is short of a large energy storage, regulation and control link, and the instability of the wind power is not welcome and unwilling to accept the grid" [5]. Under the situation of the lack of wind power consumptive ability, using wind power generation of hydrogen as attempts to alleviate wind power instability can be expected.

At present foreign representative is the ENERTRAG integrated power plant of Brandenburg Prenzlau city in German.The plant is using wind energy, hydrogen energy, biomass energy and solar energy hybrid power, and putting the emphasis on the wind power generating and hydrogen producing scale production, which is the typical demonstration plant all of the world.

The wind powered hydrogen production of Hebei Construction Investment of Zhang jiakou Guyuan County has entered the construction phase, which is a design of the total installed capacity of 20 million kilowatts of wind farms, and the annual production capacity of standard cubic hydrogen is 876 . In the northeast, $49.5 \mathrm{MW}$ wind hydrogen demonstration projects of Longfeng Lake of Changling County in Jilin have also been performed on the construction.

The current problems. At present, the main factors that restrict the production of hydrogen from wind power in China are high degree of difficulty, large investment, high cost and difficulty in storage and transportation.

The project difficulties.Wind power to produce hydrogen and supporting design in the world belongs to a new topic.Just a few foreign enterprises are put on trial, and it also belongs to the stage of exploration in China.The experience in the industry is the lack of accumulation, and domestic experts and hydrogen production industry professionals and experts from the economy have dissenting opinions, then local governments lack of interest.

The principle of the powered hydrogen production is through the electrode reaction separation of high purity hydrogen,and the large-scale engineering of equipment needs a lot of water, while China's wind power consumptive difficult areas are inland, so the underground water scarcity.However the seawater is introduced into the laying of the pipeline, and it is difficult to implement in a short time, then a large number of extraction of underground water will bring new problems of local water resources balance, so the government authorities is cautious of such projects.

The high cost. From data analysis of 2015,at present the wind power tariff is about 0.5 yuan $/ \mathrm{kWh}$,and abandoned wind power electricity is about 0.25 yuan $/ \mathrm{kWh}$. if the wind power is used to make hydrogen, each 1 cubic meter of hydrogen produced needs 5.1 to $5.2 \mathrm{~kW}$. From the cost of 1 cubic meters of hydrogen per production point of view, the cost of hydrogen production costs less than 1 yuan, while the wind power generation price is 0.25 yuan $/ \mathrm{kWh}$, and the cost of wind power 
generation of electricity is only 1.25 yuan, so there is no competitive advantage. ${ }^{[4]}$

According to the current cost of equipment, the equipment cost is about 5000-7000 yuan per cubic meters/hour. Compared with the current method of hydrogen production, and the energy consumption and scale cost are at a disadvantage.

The difficulties of transportation and storage. Hydrogen transport is usually a pipeline transport,which is a long pipe transport filling cylinders, while the another one is the pipeline transport.But the hydrogen density is small, and the air density is about 1:14.5. And the other way is not efficient because of the the unit volume and density control in addition to the pipeline transportation.

It is difficult to match long distance pipeline construction and dimension in the field of wind power generation field,which is far away from the industrial concentrated area.

Wind farms are far from the intensive industrial area,so the small and medium scale hydrogen preparation is difficult to match the long distance pipeline construction and maintenance costs, while the long transport pipe and cylinder filling are difficult to meet the needs of outward transportation, so these schemes with as a single wind power project hydrogen transport scheme design has some problems.

At home has been approved the construction of wind powered hydrogen production smaller, while the large-scale built of wind powered hydrogen production also needs a certain period of time with instability, so this case is difficult to become the backbone of hydrogen source from a mass with hydrogen industry wind powered hydrogen production in the realization of large-scale production,and the only as a key with hydrogen industry is the auxiliary source of hydrogen or the variety of channels.

\section{Summary}

In China's current economic system arrangement, the national industrial planning is the basis for guiding the development of the national economy, and the energy planning departments should be active in research in order to promote the wind power industry to a more reasonable binding to other industries in the countries with the use of their dominant advantage of this industry. And we should embrace the unified planning objectives to clarify the focus of development,and to strengthen coordination combined with the development of local industries,to get special funds and subsidy policy.Variable and other industrial development problems after the passive adjustment to the national level initiative of the forward-looking design are welcomed.

\section{Acknowledgements}

Many people have made invaluable contributions, both directly and indirectly to my research. I would like to express my warmest gratitude to my supervisor and my husband.Without the invaluable help and generous encouragement, the present thesis would not have been accomplished.

\section{References}

[1]The situation of wind power abandoned wind power rationing is intensified, the National Energy Bureau data, 2016.02.02

[2]From the global wind energy council data, 2016.1.3

[3]From Zhejiang provincial development and Reform Commission,2014.8.22

[4]Song Yafen,Hydrogen production from wind power is difficult[J], The new network energy channel ,2015.8.12

[5]Zheng erli,Take the lead in the era of hydrogen energy innovation[J]The China's hydrogen energy,2010.03.01

[6]Zhang xinggang,Wind Power Polygeneration: hydrogen production prospects can be expected or 
castles in the air[J],Chinese chemical daily,2015.3.26 